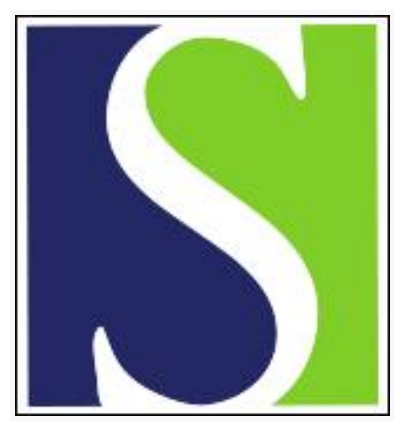

Scand J Work Environ Health 1980;6(3):216-220

https://doi.org/10.5271/sjweh.2611

Issue date: Sep 1980

Mutagenicity studies with urine concentrates from coke plant workers.

by Møller M, Dybing $\mathrm{E}$

Key terms: Salmonella typhimurium; coke plant; coke plant worker; mutagene; mutagenicity; mutagenicity study; $\mathrm{PAH}$; polycyclic aromatic hydrocarbon; urinary excretion; urine; urine concentrate

This article in PubMed: www.ncbi.nlm.nih.gov/pubmed/7010246

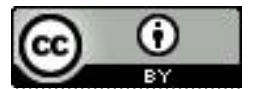




\title{
Mutagenicity studies with urine concentrates from coke plant workers
}

\author{
by Mona Møller, MSc, ${ }^{1}$ Erik Dybing, MD ${ }^{2}$
}

\begin{abstract}
MøLLER M, DYBING E. Mutagenicity studies with urine concentrates from coke plant workers. Scand $j$ work environ health 6 (1980) 216-220. Urine from coke plant workers, collected before and after work, were tested for the content of mutagenic substances in the Salmonella test system. Urine extracts from exposed smokers showed mutagenic activity, whereas urine from exposed nonsmokers did not. The mutagenicity of exposed smokers' urine was not significantly different from that of urine from nonexposed smokers. Mutagenicity of smokers' urine was only evident in the presence of a rat liver metabolic activation system. The addition of $\beta$-glucuronidase did not enhance the mutagenic effect. The facts that coke plant workers are exposed to very high levels of polycyclic aromatic hydrocarbons (PAH) and that there is no observed enhanced mutagenicity of their urine indicate that the mutagenicity observed with urine from smokers is not due to conventional PAH.
\end{abstract}

Key terms: mutagens, polycyclic aromatic hydrocarbons, Salmonella typhimurium, urinary excretion.

\section{Introduction}

Workers in coke plants are exposed to high concentrations of coal tar pitch volatiles containing a large number of polycyclic aromatic hydrocarbons (PAH), some of which [including benzo(a)pyrene (BP)] have been reported to be carcinogenic (8). Such workers are under an increased risk of cancer of the lungs and respiratory tract, and also of the urinary bladder $(3,4,5,12)$. A recent study showed that coke plant workers were exposed to $\mathrm{PAH}$ concentrations of between 5 and $1,000 \mu \mathrm{g} / \mathrm{m}^{3}$, and up to 39 different $\mathrm{PAH}$ and heterocyclic compounds were identified (2). Smokers, who are exposed to much lower concentrations of PAH, are also known to have elevated risks of bladder cancer (13).

1 Central Institute for Industrial Research, Blindern, Oslo, Norway.

2 Department of Toxicology, National Institute of Public Health, Oslo, Norway.

Reprint requests to: Ms Mona Møller, Central Institute for Industrial Research, POB $\mathbf{3 5 0}$ Blindern, Oslo 3, Norway.
A modification of the Salmonella mutagenicity test using concentrates of human urine has been suggested as a convenient assay for demonstrating exposure to mutagens/carcinogens (17). This system has been used to detect mutagenic substances in the urine of smokers (17), rubber workers (6), and anesthesiologists (9). In the present study we have examined urine from smoking and nonsmoking coke oven workers for mutagenic activity and compared these findings with results from nonexposed smokers and nonsmokers.

\section{Materials and methods}

\section{Chemicals}

Aroclor 1254 was purchased from Monsanto Chemical Co, USA, and glucose-6phosphate and NADP (sodium salt) were obtained from Sigma, USA. Dimethylsulfoxide (DMSO) and $\beta$-glucuronidase (Patella vulgata) were purchased from Koch Light Laboratories, England, and the Amberlite XAD-2 resin came from Supelco Inc, USA. 


\section{Urine samples}

Urine samples were collected from 10 smokers and 10 nonsmokers working in a coke plant. All of the smokers rolled their own cigarettes and smoked between $10-20$ cigarettes/d. Seven persons (5 smokers, 2 nonsmokers) worked at the battery, 10 (4 smokers, 6 nonsmokers) were truck drivers and 3 ( 1 smoker, 2 nonsmokers) were shift foremen. The occupational exposure varied a great deal among the workers within each group, but the two groups of workers were considered comparable with respect to the degree of exposure. Samples were taken from both the morning urine (or urine passed before a worker went on a shift) and the first urine passed after the worker quit work for the day. They were kept in glass bottles at $-20^{\circ} \mathrm{C}$ until analysis.

In addition, morning and evening urine samples from six smokers and four nonsmokers not occupationally exposed to PAH were studied. The smokers smoked between $10-40$ cigarettes $/ \mathrm{d}$, rolling their own cigarettes or smoking commercial cigarettes with or without a filter.

The samples were thawed shortly before loading on XAD-2 resins. Precipitated matter was removed by centrifugation, and the pellets were discarded before the urine was passed through the column.

\section{$X A D-2$ resin}

The XAD-2 resin was washed before use (17). Urine samples of $100 \mathrm{ml}$ were loaded on the resin with an effluent flow rate of $2-3 \mathrm{ml} / \mathrm{min}$; the column was then washed with $1.5 \mathrm{ml}$ of water and eluted with 10 $\mathrm{ml}$ of acetone according to Yamasaki \& Ames (17). The samples were evaporated to near dryness, $0.4 \mathrm{ml}$ of DMSO was added, and the rest of the acetone was removed by evaporation. A standard volume of $100 \mathrm{ml}$ of urine was applied to the resin, as the mutagenic activity per milliliter of urine decreases with increasing amounts of urine (17, and own unpublished observations). Various amounts of the DMSO extract were tested for mutagenicity. In a test of the recovery from the resin, $50 \mu \mathrm{g}$ of $\mathrm{BP}$ was added to $50 \mathrm{ml}$ of urine from a nonsmoker, the sample was loaded on the column, eluted as described above, and the extract was dissolved in $0.5 \mathrm{ml}$ of DMSO. The resin was then treated with acetone in a Soxhlet apparatus for $16 \mathrm{~h}$ to increase possibly the recovery, and the extract was evaporated and dissolved in $0.5 \mathrm{ml}$ of DMSO.

\section{Mutagenesis assay}

The Salmonella typhimurium strains TA 98 and TA 100 were kindly supplied by $\mathrm{Dr}$ BN Ames, Berkeley, CA, USA. Liver $9,000 \times \mathrm{g}$ supernatant fractions (S-9) were prepared from male Wistar rats injected with Aroclor $1254(500 \mathrm{mg} / \mathrm{kg}$ intraperitoneally) $5 \mathrm{~d}$ prior to preparation. The mutagenesis assay was carried out as described by Ames et al (1). To each test tube containing $2 \mathrm{ml}$ of molten top agar the following were added: $0.02-0.1 \mathrm{ml}$ of the test solution, $0.1 \mathrm{ml}$ of an overnight nutrient broth culture of the bacterial tester strain, and $0.5 \mathrm{ml}$ of the S-9 $\mathrm{mix}$ containing (per milliliter) $0.1 \mathrm{ml}$ of $\mathrm{S}-9$, $8 \mu \mathrm{mol}$ of magnesium chloride, $33 \mu \mathrm{mol}$ of potassium chloride, $5 \mu \mathrm{mol}$ of glucose6 -phosphate, $4 \mu \mathrm{mol}$ of NADP, and 100 $\mu \mathrm{mol}$ of a sodium phosphate buffer, $\mathrm{pH}$ 7.4. The ingredients were mixed and poured onto minimal medium plates. After

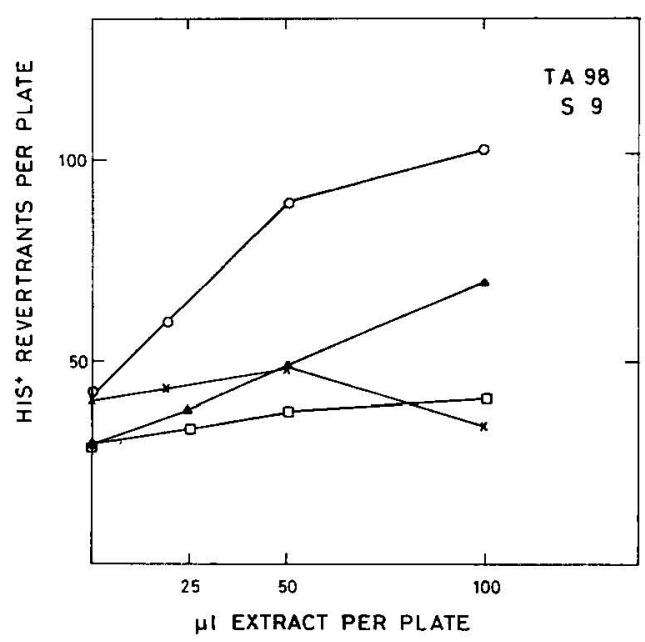

Fig 1. Concentration-dependent mutagenicity of urine extracts from exposed smokers. $\mathrm{O}-\mathrm{O}$ exposed smoker after work; $\times \longrightarrow \times$ exposed smoker before work; $\mathbf{A}-\mathbf{A}$ pooled urine concentrates from six exposed smokers after work; $\square-\square$ pooled extracts from six exposed smokers before work. Spontaneous revertants have not been subtracted. 


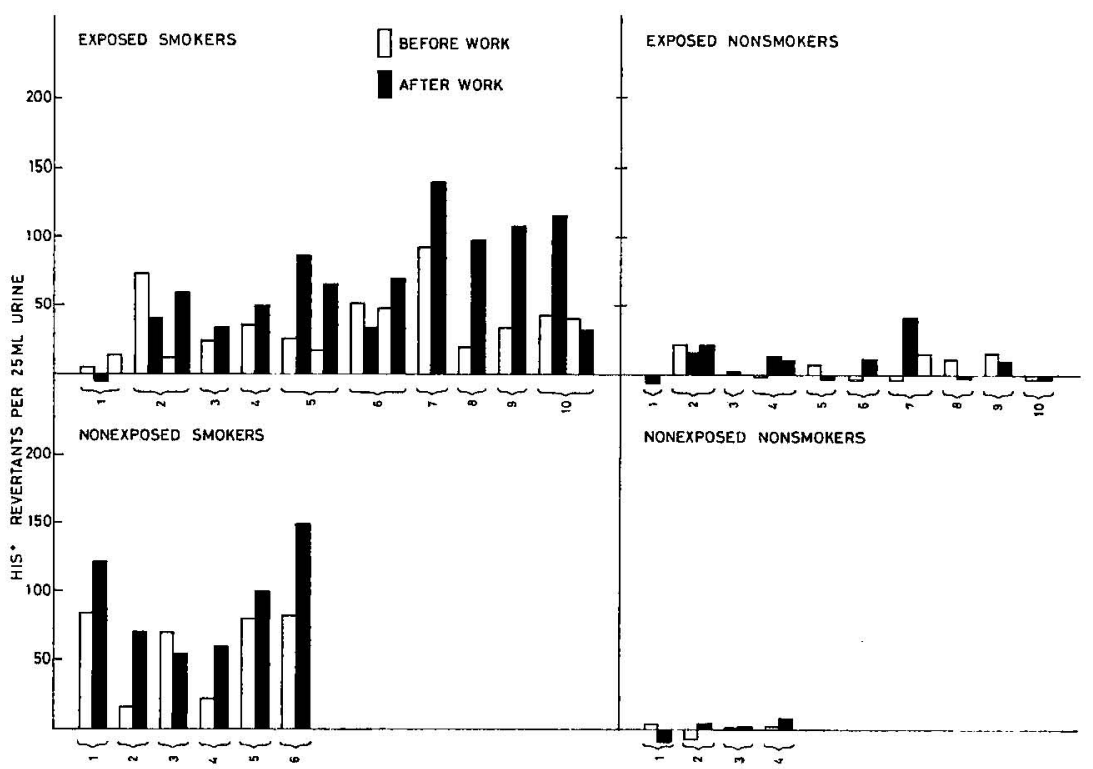

Fig 2. Individual variations in the mutagenicity of urine extracts from exposed smokers, exposed nonsmokers, nonexposed smokers and nonexposed nonsmokers. The samples were treated as described in the Materials and Methods section. Each bar represents one urine sample, and mutagenicity is expressed as revertants per $25 \mathrm{ml}$ of urine. Spontaneous revertants, 35 colonies per plate, have been subtracted. Each test person is referred to by number.

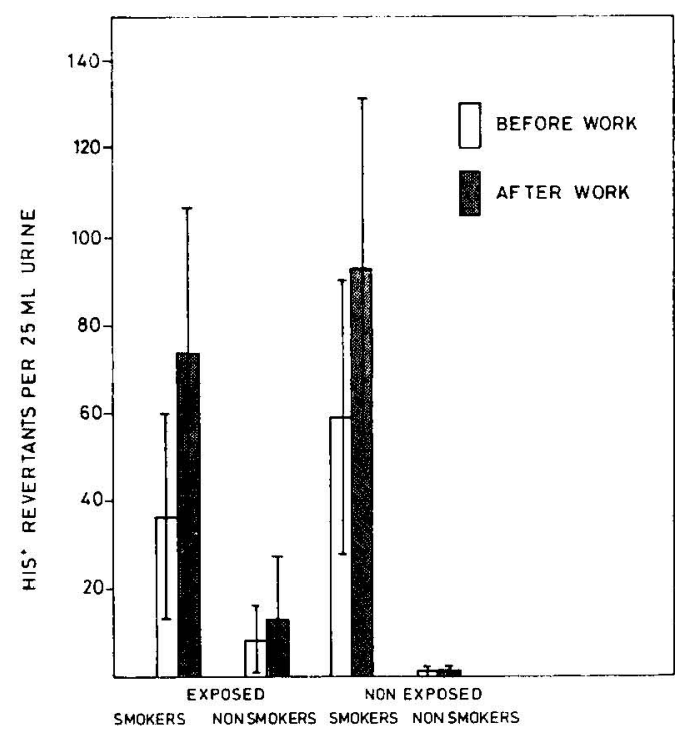

Fig 3. Mean $\pm S D$ values of the mutagenicity of urine extracts from the four different categories of persons tested.

$2 \mathrm{~d}$ of incubation at $37^{\circ} \mathrm{C}$, histidine revertant colonies were scored. The results are reported as means of duplicate plates, and most experiments were repeated once. Preliminary results revealed that very little or no mutagenic activity was ob- served with strain TA 100 . Strain TA 98 was therefore used for further studies. With this strain spontaneous revertants were $35 \pm 6(\mathrm{~N}=12)$ per plate. Differences in the results of groups were checked for statistical significance with Student's t-test.

\section{Results and discussion}

Based on the mutagenic activity of the sample when compared with the activity of BP (518 revertants $/ 5 \mu \mathrm{g})$ with strain TA 98 , a $56 \%$ recovery of $\mathrm{BP}$ from the resin was obtained when BP was added to nonsmokers' urine. This is a reasonable recovery, which could only be increased by $4 \%$ after treatment of the resin with acetone in a Soxhlet apparatus for $16 \mathrm{~h}$. In comparison, Yamasaki \& Ames reported a recovery of only $19 \%$ with BP (17).

Fig 1 shows the concentration-dependent mutagenicity of the urine concentrate from one exposed smoker and of pooled concentrates from six exposed smokers tested in strain TA 98 in the presence of S-9 mix. No activity was observed in the absence of the S-9-mix. 
The results from the testing of individual samples are given in fig 2 as revertants per $25 \mathrm{ml}$ of urine $(0.1 \mathrm{ml}$ of DMSO extract). It was found that urine from exposed smokers contained substances which could be activated to mutagens in the Salmonella test. However, the mutagenicity of samples from exposed smokers was not significantly different from that of samples from nonexposed smokers at the $95 \%$ significance level. The mutagenicity of the urine extracts from exposed workers was higher for most samples taken after than for those taken before work; the situation was the same for nonexposed smokers. The mutagenic activity of urine from exposed nonsmokers was not significantly different at the $95 \%$ level when compared to the mutagenic activity of the urine samples from nonexposed nonsmokers or to the number of spontaneous revertants.

Fig 3 shows the mean values of the mutagenicity of the tested samples from exposed smokers and nonsmokers, as well as from nonexposed smokers and nonexposed nonsmokers.

Many metabolites of xenobiotic compounds are excreted in the urine as conjugates such as glucuronides and sulfates, some of which can be hydrolyzed by enzymes present in the S-9 fraction. Further addition of $\beta$-glucuronidase to the urine extracts did not lead to any enhanced mutagenic effects in strain TA 98 .

In a coke plant the $\mathrm{PAH}$ exposure varies strongly with the type of job. Bjørseth et al (2) reported that BP concentrations for different job types varied between 0.5 and $43.2 \mu \mathrm{g} / \mathrm{m}^{3}$ for personal sampling and between 14 and $134 \mu \mathrm{g} / \mathrm{m}^{3}$ for stationary sampling. A suggestion of higher mutagenic activity of urine extracts from high exposure workers compared with lower exposure workers was found. One would, however, need a much greater number of samples to verify this possible difference statistically.

The present method has been proposed as a general screening procedure to detect unsuspected mutagens/carcinogens in human urine (17). However, the possibility of detecting mutagenic activity with this test would be dependent on the chemical nature of the excretory products. PAH, being very apolar, would only be excreted in very small amounts unchanged. More polar metabolites, such as phenols, dihydrodiols or quinones, can be excreted as such, or they form water-soluble conjugates with glucuronic and sulfuric acids. Certain phenols $(7,10,16)$ and dihydrodiols $(15,16)$ of PAH are known to be activated to mutagens in the Salmonella test. Conjugates could conceivably be first hydrolyzed and then activated by microsomal monooxygenases. It is highly improbable that the short-lived, ultimate mutagenic species of PAH, the diolepoxides (15), would be excreted in urine.

The content of unmetabolized BP in urine from coke oven workers has recently been stated to vary between 0.9 and 11.3 $\mu \mathrm{g} / 1$ (14), and the BP content of smokers' urine in the evening was determined to lie between 0.11 and $0.51 \mu \mathrm{g} / 1$ (11). The concentration of other possibly mutagenic $\mathrm{PAH}$ in the urine of coke oven workers or smokers is not known.

The present study shows that workers who are exposed to high concentrations of $\mathrm{PAH}$ do not excrete significant amounts of mutagens in their urine when they refrain from smoking. On the other hand, Doll et al (5) have shown that there is an increased risk of bladder cancer in coke oven workers. This increment could not be ascribed to a difference in the smoking pattern of the workers and controls (4). One might speculate that exposure to promoting factors could be involved in the development of bladder cancer in exposed workers, since the mutagenic activity of urine could not be demonstrated. As smokers are exposed to much lower concentrations of PAH than coke oven workers, it is probable that these compounds are not the mutagenic principles in smokers' urine. More probable candidates are aromatic amine pyrolysates, which have been shown to be potent mutagens and to occur in high concentrations in cigarette smoke condensates (13).

\section{Acknowledgment}

We wish to thank O Storsæter, MD, Norsk Jernverk, for his kind cooperation in collecting the urine samples and Ms A 
Osvik and Ms M-B Jørgensen for their skillful technical assistance.

This study was supported by the Royal Norwegian Council for Scientific and Industrial Research.

\section{References}

1. Ames BN, McCann J, Yamasaki E. Methods for detecting carcinogens and mutagens with the Salmonella/mammalian microsome mutagenicity test. Mutat res 31 (1975) $347-364$.

2. Bjørseth A, Bjørseth O, Fjeldstad PE. Polycyclic aromatic hydrocarbons in the work atmosphere: II. Determination in a coke plant. Scand j work environ health 4 (1978) 224-236.

3. Collings PL. Coke workers' mortality: A nine year follow-up study in the British steel industry. Institute of Occupational Medicine, Edinburgh 1978. (Report No TM/ 78/1 (1978)).

4. Doll R, Fisher REW, Gammon EJ, Gunn W, Hughes GO, Tyrer FH, Wilson W. Mortality of gas-workers with special reference to cancers of the lung and bladder, chronic bronchitis, and pneumoconiosis. $\mathrm{Br} \mathrm{j}$ ind med 22 (1965) $1-2$.

5. Doll R, Vessey MP, Beasley RWR, Buchley AR, Fear EC, Fisher REW, Gammon EJ, Gunn W, Hughes GO, Lee K, NormanSmith B. Mortality of gas-workers Final report of a prospective study. $\mathrm{Br} \mathbf{j}$ ind med 29 (1972) $394-406$.

6. Falck K, Skyttä E, Kilpikari I, Sorsa M, Vainio $H$. Mutagenicity in urine of rubber workers. In: Meeting abstracts of the European Environmental Mutagen Society, Yugoslavia 1979.

7. Glatt $\mathbf{H}$, Oesch F. Phenolic benzo(a)pyrene metabolites are mutagens. Mutat res 36 (1976) $379-384$.

8. International Agency for Research on Cancer. IARC monographs on the

Received for publication: 1 February 1980 evaluation of the carcinogenic risk of chemicals to man: Certain polycyclic aromatic hydrocarbons and heterocyclic compounds. Vol 3. Lyon 1973.

9. McCoy, Hankel R, Rosenkranz HS, Giuffrida JG, Bizzari DV. Detection of mutagenic activity in the urines of anesthesiologists: A preliminary report. Environ health perspec 21 (1977) $221-223$.

10. Owens IS, Koteen GM, Legraverend C. Mutagenesis of certain benzo(a)pyrene phenols in vitro following further metabolism by mouse liver. Biochem pharmacol 28 (1979) 1615-1622.

11. Repetto $M$, Martinez $D$. Benzopyrène de cigarettes et son excrétion urinaire. J europ toxicol 7 (1974) 234-237.

12. US Department of Health, Education, and Welfare. Smoking and health: A report of the Surgeon General. Washington, DC 1979.

13. Sato $S$, Seino $Y$, Ohka $T$, Yahagi $T$, Nagao M, Matsushima $T$, Sugimura $T$. Mutagenicity of smoke condensates from cigarettes, cigars and pipe tobacco. Cancer lett 3 (1977) $1-8$.

14. Szyja J. Untersuchungen über den 3,4Benzpyrengehalt an Arbeitsplätzen der Pechofenbatterie einer Kokerei und in Körperflüssigkeiten der Arbeiter. $\mathrm{Z}$ ges Hyg Grenzgeb 7 (1977) 440-442.

15. Wood AW, Levin W, Chang RL, Yagi H, Thakker DR, Lehr RE, Jerina DM, Conney AH. Bay-region activation of carcinogenic polycyclic hydrocarbons. In: Jones PW, Leber $\mathbf{P}$, ed. Polynuclear aromatic hydrocarbons. Ann Arbor Science Publishers, Ann Arbor, MI 1979, pp 531-551.

16. Wood AW, Levin W, Lu AYH, Yagi $Y$, Hernandez O, Jerina DM, Conney AH. Metabolism of benzo(a)pyrene and benzo(a)pyrene derivates to mutagenic products by highly purified hepatic microsomal enzymes. J biol chem 251 (1976) 4882-4890.

17. Yamasaki E, Ames BN. Concentration of mutagens from urine by adsorption with the nonpolar resin XAD-2: Cigarette smokers have mutagenic urine. Proc natl acad sci 74 (1977) 3555-3559. 